\title{
Re-thinking, connecting, sharing and starting synergies. Using a collaborative AGORA session for new educational and research connections.
}

\author{
David Fonseca ${ }^{\dagger}$ \\ GRETEL - Group of Research on \\ Technology Enhanced Learning. \\ La Salle / Ramon Llull University \\ Barcelona, Spain \\ David.fonseca@salle.url.edu
}

\author{
Marc Alier \\ Barcelona Science and Engineering \\ Education Research Group \\ Polytechnic University of \\ Catalonia-Barcelona Tech \\ Barcelona, Spain \\ Marc.alier@upc.edu
}

\author{
Patricia Sánchez-Holgado \\ Observatory for Audiovisual \\ Contents. \\ Faculty of Social Sciences. \\ University of Salamanca \\ Salamanca, Spain \\ Patriciasanc@usal.es
}

\begin{abstract}
The objective of the session is to establish a collaborative dynamic that allow the participant to work in a CO-THINKING and CO-CREATION dynamics. We want to share and develop ideas, concepts, keywords, projects (finished, in progress and/or maybe in an initial state) in order to establish a CONCEPTUAL MAP that relates in an initial and dynamic Eco-System, the main approaches, techniques, systems or methodologies that can improve the processes in progress of the attendance.
\end{abstract}

\section{CCS CONCEPTS}

- General and reference $\sim$ Cross-computing tools and techniques $\sim$ Design • Information systems $\sim$ Data management systems Data structures Data layout • Human-centered computing Human computer interaction $(\mathrm{HCI}) \sim \mathrm{HCI}$ design and evaluation methods $\sim$ User studies - Social and professional topics $\sim$ User characteristics $\bullet$ Applied computing $\sim$ Education

\section{KEYWORDS}

Pedagogic design, New educational methodologies, Teamwork, Analysis.

\section{ACM Reference format:}

David Fonseca, Marc Alier, and Patricia Sánchez-Holgado. 2020. Rethinking, connecting, sharing and starting synergies. Using a collaborative AGORA session for new educational and research connections. In Proceedings of Technological Ecosystems for Enhancing Multiculturality (TEEM'20). Salamanca, SPA, 5 pages. https://doi.org/XXXXX

\section{Introduction}

All of us are constantly thinking, creating, implementing, evaluating, publishing, etc., some type of innovative proposals to improve education, professional activities, in other words... our current, and future society. However, and perhaps because of a

Re-thinking, connecting, sharing and starting synergies. Using a collaborative AGORA session for new educational and research connections.

†David Fonseca, Marc Alier and Patricia Sánchez-Holgado

Permission to make digital or hard copies of part or all of this work for personal or classroom use is granted without fee provided that copies are not made or distributed for profit or commercial advantage and that copies bear this notice and the full citation on the first page. Copyrights for third-party components of this work must be honored. For all other uses, contact the owner/author(s).

TEEM'20, October, 2020, Salamanca, SPA lack of time or proper forum, we rarely stop to explain, share or listen to alternative and dynamic ways about our ideas/projects and to relate all these proposals in a correct way with research methodologies, ideas, results, analysis and new developments.

Potentially, our own colleagues, professionals or individuals from other sectors, and even potential end-users, can help us in these processes/projects, establishing new synergies that allow a more efficient, effective and satisfactory way to carry them out.

From a basic presentation of the work that each participant wants to exhibit orally and on whiteboard support (3 maximum, having digital presentation for image/video support), the ideas and concepts will be complemented with the following presentations. After each presentation, the relevant methods, systems, technologies, approaches and aspects of each proposal will be identified, and will be linked to the other proposals as they are presented.

With the identification of the methods, systems, technologies, uses and proposals that each participant is using and based on the comments, ideas, and in general participation of the rest of the attendees arises the definition of new synergies between people, research groups and universities that enrich the TEEM as a meeting point and focus of improving multidisciplinary work at any level.

\section{Context}

Education is currently one of the sectors in which innovation is of great concern [12,23,24].

In the case of Spain, some of the challenges it faces are, for example, reducing school drop-outs, reforming the teaching career, reducing early school leaving, stimulating language learning, increasing public spending on education, increasing education continuous in adults and reduce the mismatch between education and the labor market, among others. (European Commission, 2019).

It can be seen that the education sector faces multiple challenges, in all its areas, and one of the ways to face these challenges is by adapting the teaching objectives, focusing on the student's competencies and not only on their knowledge. (Roegiers, 2016) 
At present, many of the educational systems combine the competency approach with the traditional approach, but trying to apply an evolution towards the latter model. Whatever role competencies should play in curricula, they can be summarized in three common denominators (Roegiers, 2010)

1. The content of the teaching goes beyond knowledge and know-how. Education goes beyond the school itself, as it is influenced by its context on issues such as culture, values, information, employment, etc., so it has to cover content related to these issues as a common need. The need you face is to consider new knowledge, new content or content categories, such as life skills or transversal skills.

2. The main actor in learning is the student. The student has to be an active participant in her own educational process. In addition, this requirement is directly related to the new teaching roles, because they are shown as guides, advisers or mentors who support the student in their personal development. They no longer have a unidirectional and hierarchical role.

3. Knowing how to act in certain situations is valued. Managing complex situations is an element of learning itself. When speaking of a competency-based approach, there are different opinions about it, but they all agree on the importance of knowing how to deal with situations that are not the usual ones. (Roegiers, 2016)

If we consider the capacity of our institutional model to educate and train our students and tomorrow's professionals with the latest methodologies and technologies available, we can safely say that our pedagogical design is effective $[2,6,17,18]$. Over the year, our pedagogic design has adapted to both the profile of the students and to market demands.

Furthermore, in recent years, there have numerous initiatives, led by both government and local authorities and by private companies, which have tried to move away from traditional learning practices and foment more up-to-date methods in line with current trends and the changing paradigms of today's society $[11,21,22]$.

Teamwork $[1,16,19]$, project or challenge based learning $[10,27,28]$, gamification $[7,25,26]$, or the use of any type of digital support, are just some of the methods and systems that have taken a more prominent role in the classroom and which place the student in the centre of the educational process. This is when the student thinks, reflects, shares, creates, questions and debates and when he or she really learns. These methodologies are a far cry from the traditional unidirectional transfer of content from teacher to student $[13,14]$.

But what is happening with teachers and researchers? How they are managing and sharing their proposal, ideas and needs? What are their needs to connect educational innovations with research and needs? What are the best forums to be actualized? People in general, teachers and researchers also, feel comfortable when information is recommended by someone they know and trust. The purpose of education is to share your knowledge with others, students and with your colleagues in order to improve your approaches. By sharing, the teacher and the researcher enables colleagues to empower their students even more, the main contribution of the AGORA-EcoSystem session in TEEM 2020.

Educational/Research data usability and accessibility is even more relevant in the context of the global pandemic due to the SARS-CoV-2 virus, which causes COVID-19 disease. This situation is having an unprecedented impact on education, and also in educational research. Consequently, it is vital to improve access to educational technologies and reduce gaps in use and literacy. A multi-disciplinary approach is required to deploy technological ecosystems that favor blended or online training, teacher and student training for the efficient use of educational technologies, and policies for both government and academic leaders to define strategies and manage uncertain scenarios $[4,5,8]$. In the context of educational data access, it is critical to ensure transparency, ethics, and individuals' rights.

\section{AGORA-EcoSystem activity and results.}

\subsection{The Proposals}

The dynamics had the registration of 12 participants in the framework of the TEEM Congress. From a free presentation of 35 minutes on the topics of work, or interest of the speakers, those concepts or variables that have aroused the most interest or debate have been identified. The objective was to establish relationships between said concepts, variables, ideas or interests, even that such relationships can be established between researchers for future interactions that may lead to institutional collaborations and / or research proposals and research projects in the educational environment.

After the presentations of the speakers, multiple concepts have been extrapolated as a cause for debate and origin of ideas or links between the attendees and their work.

Based on the debate and joint work, the following key aspects have been identified:

- Need to promote the dissemination of the results (Fig. $1)$.

- Sustainable Development Goals and field work to collect informal data on climate change (Fig. 2).

- I work with transversal skills to improve education.

- Dialectics as a conflict resolution process.

- State of the art in the field of Learning Analytics to identify partners of interest.

- The identification of partners in an area allows you to maximize the impact and dissemination of that area.

- Citizens' perception of complex aspects related to research (Big Data, Artificial Intelligence, etc.)

- How these complex aspects are dealt with in the media, a fundamental aspect in scientific dissemination and in adapting to the heterogeneous profiles that receive the information (Fig. 3).

- Working with Learning Analytics activates other related fields little studied and of vital importance:

- Ethics on all data used

- Validation of measurement proposals 
Re-thinking, connecting, sharing and starting synergies. Using a collaborative AGORA session for new educational and research connections

○ Rigor in data processing (Fig. 4).

- Bringing science and research together in a simple way generates motivation and interest, and potential partnerships.

- The new digital generation is connected to the media, and only that information correctly disseminated generates the interest that research may need for its development.

- Strengthen competencies and skills to promote entrepreneurship and that educational proposals improve business ideas, being more resilient and permanent over time (this last contribution sent later via email due to connection problems).

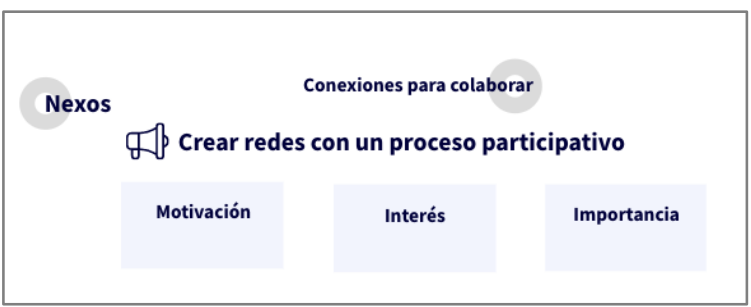

Figure 1: Collaboration starting point

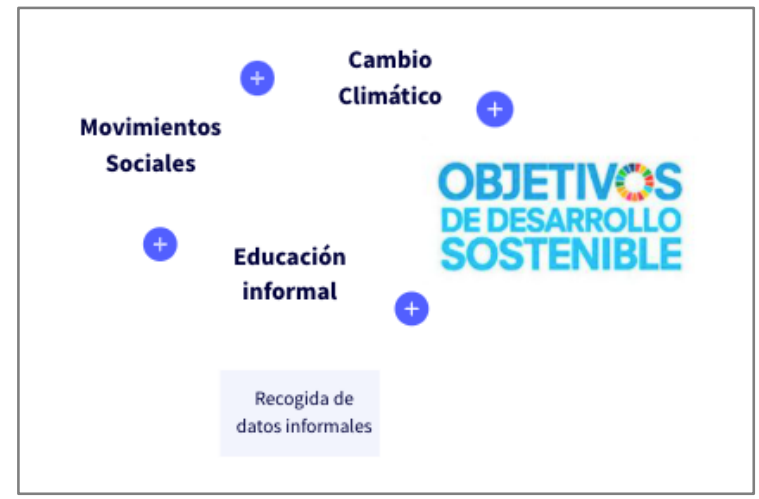

Figure 2: Informal education and sustainable development

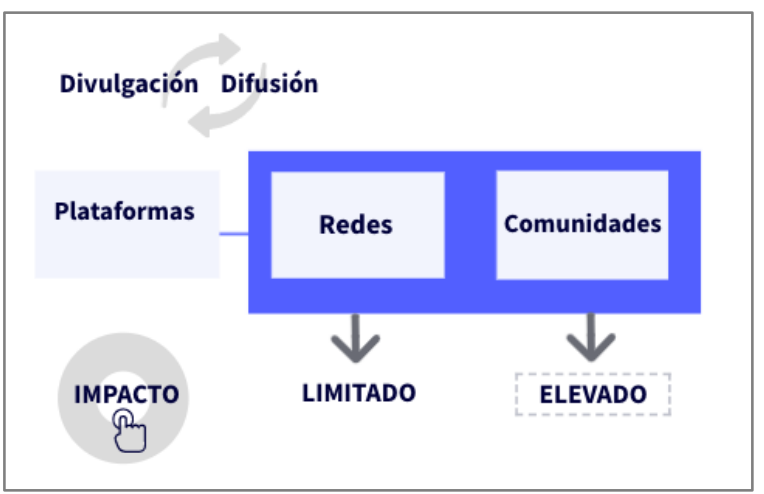

Figure 3: Communication, outreach and impact.

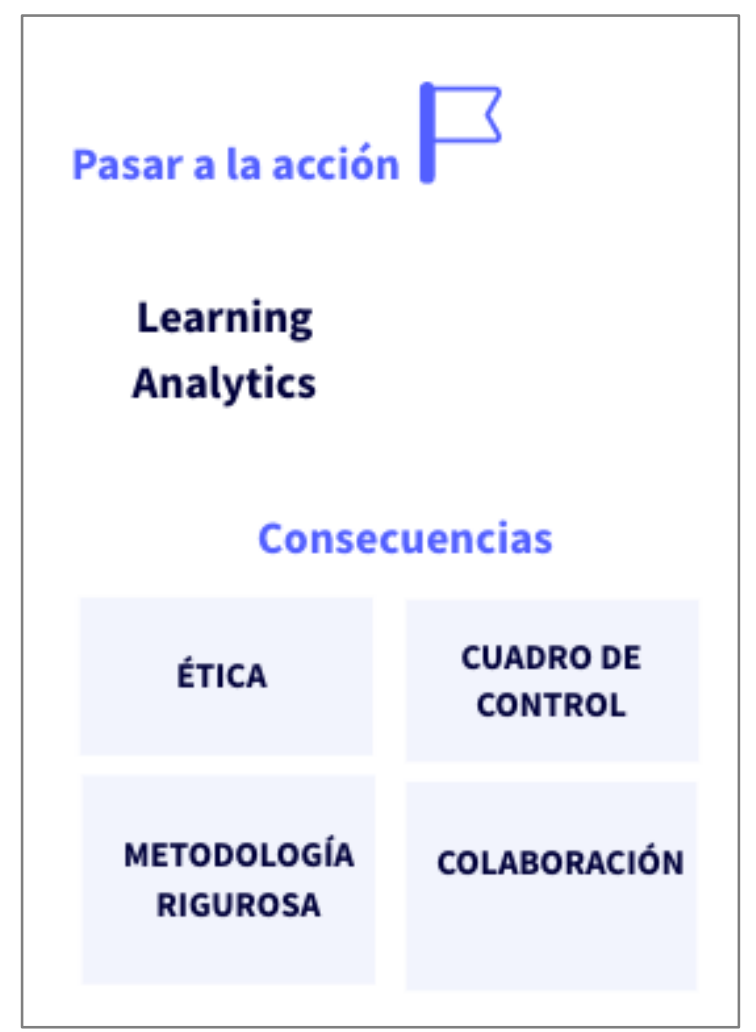

Figure 4: Learning analytics and its consequences

\subsection{The Relations}

In Fig. 5, we can see the relationships between the keywords identified in AGORA.

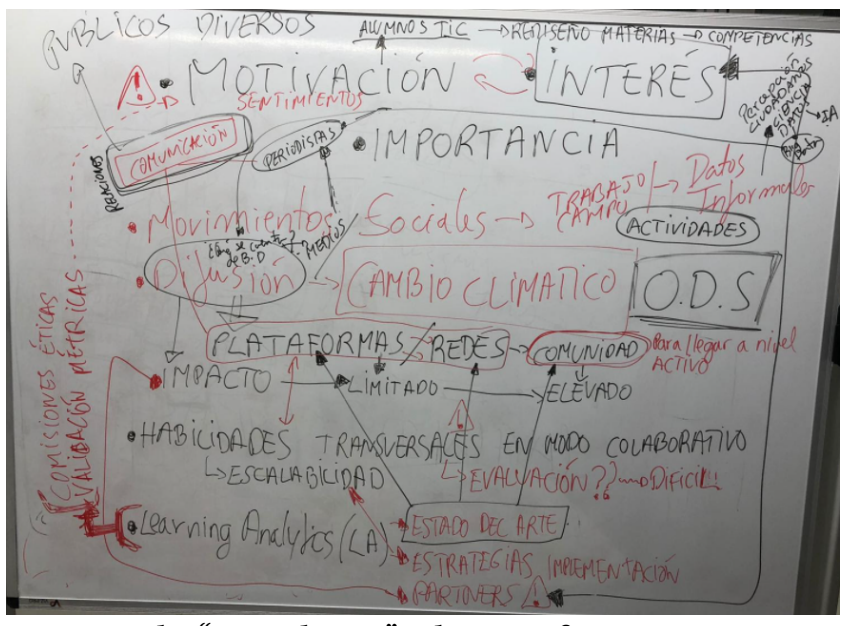

Figure 5: The "on real-time" relations of AGORA. 
The relationships carried out in real time, and which we have listed in the points stated in the previous section, allow us to define two main categories:

- Topics:

○ SDGs applied to any field of education and research.

- Learning Analytics as a basis in the treatment of educational data, in an ethical, secure, private and validated way.

- Competences (specific \& generic), as a framework for improvement, comparison and evaluation of educational innovations and research.

- Approaches:

- Identify channels of diffusion and dissemination

- Adapt message and information to the end user

- Correctly transmitted information generates motivation and interest in it.

\section{Conclusions}

In this first edition of AGORA we have seen the effectiveness of a session managed informally and exceptionally in virtual for the identification and connection of ideas, concerns and potentialities of research in the educational field. Regardless of the most personal and concrete issues identified and enunciated, a common background is observed: the importance of communication.

There are three fundamental parameters that describe the relations of society with science to better guide communication: perception and social attitudes towards science and technology, the scientific-technical culture of a society and the interest of citizens in science. Without social communication of science it is impossible to achieve scientific culture. One of the paradigms of scientific culture is that of the involvement of the public with science (Godin \& Gingras, 2000) the two types of components are mixed: the level of scientific literacy of the public and the type of positive or negative attitude towards science. science. However, the presence of scientific content in the audiovisual media is still very scarce (Moreno Castro, 2010).

Finding and using the most appropriate platforms, networks and communities for each development, as well as creating a language that allows all types of profiles to understand it is a fundamental aspect of the research, since: it increases the impact, motivation and interest. These three factors are key to establishing synergies, collaborations and obtaining financing in the development of projects.

Likewise, the message that is communicated must be reliable and validated. In research with educational data, a certain laxity in the treatment of data is glimpsed, with nonvalidated instruments that generate biases, little interest in the privacy and security of the data, and still a certain lack of control in the ethical parameters of the same.

In summary, these conclusions are proposed as the starting point for TEEM-AGORA-21, with the aim of helping the scientific community in the dissemination and dissemination of data from their research as the main aspect to develop to increase their impact. .

\section{REFERENCES}

[1] Emily Britton, Natalie Simper, Andrew Leger, and Jenn Stephenson 2017. Assessing teamwork in undergraduate education: a measurement tool to evaluate individual teamwork skills. Assess. Eval. High. Educ. 42 , 3 (2017), 378-397. DOI:https://doi.org/10.1080/02602938.2015.1116497

[2] Zewditu Demissie, Nancy D Brener, Tim Mcmanus, Shari L Shanklin, Joseph Hawkins, and Laura Kann. 2014. School Health Profiles 2014: Characteristics of Health Programs Among Secondary Schools. Sch. Heal. Profiles (2014), 1-197. Retrieved from http://www.cdc.gov/healthyyouth/data/profiles/results.htm

European Union. 2016. Education and Training Monitor 2016 - Executive Summary.

[4] David Fonseca, Miguel Ángel Conde, and Francisco J. García-Peñalvo. 2018. Improving the information society skills: Is knowledge accessible for all? Univers. Access Inf. Soc. 17, 2 (2018), 229-245. DOI:https://doi.org/10.1007/s10209-017-0548-6

[5] David Fonseca and Francisco José García-Peñalvo. 2019. Interactive and collaborative technological ecosystems for improving academic motivation and engagement. Universal Access in the Information Society 18, 423-430. DOI:https://doi.org/10.1007/s10209-019-00669-8

[6] David Fonseca, Nuria Martí, Ernesto Redondo, Isidro Navarro, and Albert Sánchez. 2014. Relationship between student profile, tool use, participation, and academic performance with the use of Augmented Reality technology for visualized architecture models. Comput. Human $\begin{array}{llll}\text { Behav. } & 31, & 1 & \text { (2014), }\end{array}$ DOI:https://doi.org/10.1016/j.chb.2013.03.006

[7] David Fonseca, Sergi Villagrasa, Isidro Navarro, Ernest Redondo, Francesc Valls, and Albert Sánchez. 2017. Urban gamification in architecture education. In Advances in Intelligent Systems and Computing, 335-341. DOI:https://doi.org/10.1007/978-3-319-56541-5_34

[8] Alicia García-Holgado and Francisco José García-Peñalvo. 2019. Validation of the learning ecosystem metamodel using transformation rules. Futur. Gener. Comput. Syst. 91, (2019), 300-310. DOI:https://doi.org/10.1016/j.future.2018.09.011

[9] Benoit Godin and Yves Gingras. 2000. What is scientific and technological culture and how is it measured? A multidimensional model. Public Underst. Sci. 9, 1 (2000), 43-58. DOI:https://doi.org/10.1088/0963-6625/9/1/303

[10] Cindy E. Hmelo-Silver. 2004. Problem-based learning: What and how do students learn? Educational Psychology Review 16, 235-266. DOI:https://doi.org/10.1023/B:EDPR.0000034022.16470.f3

[11] Stephen Kemmis, Jane Wilkinson, Christine Edwards-Groves, Ian Hardy, Peter Grootenboer, and Laurette Bristol. 2014. Changing practices, changing education. DOI:https://doi.org/10.1007/978-981-4560-47-4

[12] Jane Knight. 2011. Education Hubs: A Fad, a Brand, an Innovation? Journal of Studies in International Education 15, 221-240. DOI:https://doi.org/10.1177/1028315311398046

[13] Heather Lotherington and Jennifer Jenson. 2011. Teaching multimoda and digital literacy in L2 settings: New literacies, new basics, new pedagogies. Annual Review of Applied Linguistics. DOI:https://doi.org/10.1017/S0267190511000110

[14] Michele Monaco and Malissa Martin. 2007. The Millennial Student: A New Generation of Learners. Athl. Train. Educ. f. (2007) DOI:https://doi.org/10.4085/1947-380x-2.2.42

[15] Carolina Moreno Castro. 2010. La construcción periodística de la ciencia a través de los medios de comunicación social: hacia una taxonomía de la difusión del conocimiento científico. Artefactos 3 (2010), 109-130.

[16] Silvia Necchi, Enric Peña, David Fonseca, and Marc Arnal. 2020 Improving teamwork competence applied in the building and construction engineering final degree project. Int. 7. Eng. Educ. 36, 1 B (2020), 328-340.

[17] Katherine G. Nelson, Duane F. Shell, Jenefer Husman, Evan J. Fishman, and Leen Kiat Soh. 2015. Motivational and self-regulated learning profiles of students taking a foundational engineering course. F. Eng Educ. 104, 1 (2015), 74-100. DOI:https://doi.org/10.1002/jee.20066

[18] M. T. Pillen, P. J. Den Brok, and D. Beijaard. 2013. Profiles and change in beginning teachers' professional identity tensions. Teach. Teach. Educ. 
Re-thinking, connecting, sharing and starting synergies. Using a collaborative AGORA session for new educational and research connections

34, (2013), 86-97. DOI:https://doi.org/10.1016/j.tate.2013.04.003 Linda Riebe, Antonia Girardi, and Craig Whitsed. 2016. A Systematic Literature Review of Teamwork Pedagogy in Higher Education. Small Gr. Res. 47, 6 619-664. DOI:https://doi.org/10.1177/1046496416665221

[20] Xavier Roegiers. 2016. Marco conceptual para la evaluación de competencias. Cuest. Fundam. y actuales del currículo y el Aprendiz. 4, (2016), $45 . \quad$ Retrieved from http://www.ibe.unesco.org/sites/default/files/resources/ipr4-roegierscompetenciesassessment_spa.pdf

[21] Lambert W.T. Schuwirth and Cees P.M. Van Der Vleuten. 2004 Changing education, changing assessment, changing research? Med Educ. 38, 8 (2004), 805-812. DOI:https://doi.org/10.1111/j.13652929.2004.01851.x

[22] Sir Ken Robinson. 2010. Changing education paradigms (animated). TED Talks. Retrieved from http://www.ted.com/talks/ken_robinson_changing_education_paradigm $\mathrm{s}$

[23] Gesa Sonja and Elsa Van Den Broek. 2012. Innovative Research-Based Approaches to Learning and Teaching. OECD Educ. Work. Pap. 79 (2012), 0-31. DOI:https://doi.org/10.1787/5k97f6x1kn0w-en

[24] Maximilian Unger and Wolfgang Polt. 2017. The knowledge triangle between research, education and innovation -A conceptual discussion. Foresight STI Gov. 11, 2 (2017), 10-26. DOI:https://doi.org/10.17323/25002597.2017.2.10.26

[25] Sergi Villagrasa, David Fonseca, Ernest Redondo, and Jaume Duran 2014. Teaching case of gamification and visual technologies for education. f. Cases Inf. Technol. 16, 4 (2014), 38-57. DOI:https://doi.org/10.4018/jcit.2014100104

[26] Eva Villegas, Emiliano Labrador, David Fonseca, and Sara FernándezGuinea. 2019. Methodology I'M IN applied to workshop: successful educational practice for consultants in user experience with gamification fields. Univers. Access Inf. Soc. 18, 3 (2019), 507-521. DOI:https://doi.org/10.1007/s10209-019-00675-w

[27] Clarice Wirkala and Deanna Kuhn. 2011. Problem-based learning in k-12 education: Is it effective and how does it achieve its effects? Am. Educ
$48, \quad 5$
(2011)
$1157-1186$.

DOI:https://doi.org/10.3102/0002831211419491

[28] Elaine H.J. Yew and Karen Goh. 2016. Problem-Based Learning: An Overview of its Process and Impact on Learning. Heal. Prof. Educ. 2, 2 (2016), 75-79. DOI:https://doi.org/10.1016/j.hpe.2016.01.004 